\title{
La condición circular de la dimensión social del e-learning. Conclusiones
}

\author{
Jordi Planella \\ Israel Rodríguez
}

Lo visto hasta ahora constituye una prueba más de hasta qué punto la explosión de una serie de tecnologías, cada vez más instaladas en el seno de nuestras relaciones y formas de comunicarnos, convulsiona nuestros límites y geografías intelectuales y políticas, antaño más o menos seguras, y nos demanda discusiones y soluciones imaginativas para hacer frente a los retos actuales. La educación, en tanto que fenómeno social y cultural, no es ajena a dichos cambios ni a la necesidad de un debate sobre sus transformaciones y su futuro papel en las sociedades y formas de interacción y convivencia que se avecinan. Tal como apunta Perelman, «lo hiper en la educación a distancia no sólo se refiere a la extraordinaria velocidad con la que hoy se desarrollan las tecnologías de la información, sino a un grado de conexión sin precedentes entre el conocimiento, la experiencia, los medios y las mentes». ${ }^{1} \mathrm{Y}$ como hemos visto, el e-learning constituye, a la par, una de las mayores esperanzas, así como una de las mayores preocupaciones para educadores, politólogos, investigadores y demás actores sociales interesados en el fenómeno educativo.

Si algo se pone de manifiesto a lo largo de los textos y discusiones que tienen lugar en este monográfico es que el e-learning es un campo tan polifacético como polisémico. Sin duda, siguiendo a Maturana, hemos visto que hay distintas y variadas formas de lenguajear el e-learning, de darle forma de palabras, de definirlo, de orientarlo, de vincularlo al mundo. ${ }^{2}$ Evidentemente, cada una de ellas conlleva correlatos e implicaciones distintas y cada una de ellas refleja y a su vez da forma a una determinada sociedad.

\section{EL CARÁCTER JÁNICO DEL E-LEARNING}

Podemos decir que el e-learning tiene un rostro jánico. Como el dios más antiguo del Lacio, el e-learning puede ser representado como una práctica formativa con más de una cara. De él sabemos que tiene doble rostro. Es puerta, porque abre y da origen a nuevas formas de relación. Es esperanza y en él depositamos el poder de una nueva sociedad, el amanecer de un nuevo día. Pero a su vez puede ser obstáculo; puede convertirse en algo que corte caminos y rutas, que anquilose los pasos en horizontes ya conocidos. Es pues también un elemento más que puede llevarnos a un horizonte repleto de repeticiones, de rostros conocidos, sumando en la desesperanza. A menudo, además, padecemos de una extraña miopía que nos lleva a defender airosamente sólo una de esas caras, como anhelando que la fuerza vertida en la discusión consiga apagar la imagen que intuimos pero negamos al otro lado del espejo. Al principio de este monográfico, sin embargo, ya hemos acentuado la poca utilidad intelectual que tiene moverse por dicotomías de este tipo, más publicitarias que reales, más estériles que lumínicas.

De nada sirve, tampoco, instalarse en ninguna forma de fatalismo. Los caminos y derroteros del e-learning dependen, y mucho, de lo que queramos hacer con él.

\footnotetext{
1 PERELMAN, L.J. (1993). Hyperlearning, The New Technology, and the End Of Education. Nueva York: Avon Books, pág. 22.

2 MATURANA, H. (1986). El árbol del conocimiento. Santiago de Chile: Editorial Universitaria.
} 
Dependen, y mucho, del destino que consigamos negociar. Pero esto no es nada evidente: de hecho buena parte del desconcierto ante los nuevos conceptos proviene precisamente de mantener y alimentar una noción fatalista con respecto al propio desconcierto. $\mathrm{O}$ bien nos aparece como algo irremisible, determinante, un imperativo sin más del progreso acuciante de la técnica y de nuestras sociedades ante el cual nos queda poco por decir y por hacer, o bien se torna un mero instrumento inocente, un operativo de gestión y optimización desposeído de papel y misiones de alto rango, ante el que tampoco hay mucho que hacer ni decir. Ambos alejan la discusión en torno al e-learning de su carácter polivalente, de su carácter social y de su dimensión política. Ambos alimentan una inercia y, por lo tanto, convierten en hecho o en fetiche lo que más bien debería ser objeto de discusión, decisión, orientación y legislación colectiva. $\mathrm{Y}$ es que no se puede discutir de problemas educativos sin hablar de problemas sociales y políticos. En este sentido nos habló Marco. A. Dias cuando planteaba que «soy de los que consideran que no se pueden discutir los problemas referentes a la educación y a la formación sin tratar problemas sociales más amplios, más generales. Por eso me estimuló mucho que uno de ustedes pudiera escuchar a la secretaria de Inmigración de la Generalitat, que trataba este problema fundamental». ${ }^{3} \mathrm{Y}$ si no podemos discutir de problemas educativos sin discutir de problemas sociales, tampoco podremos hacerlo del e-learning sin tener en cuenta su perspectiva social.

Del mismo modo, a menudo el constructo e-learning es desplazado por la problemática del impacto social de las TIC, y lo vemos excesivamente ligado a sus utopías y esperanzas como proyecto técnico. Nuestra atención, lejos de dirigirse a una discusión serena, se dirige inmediatamente hacia preocupaciones globales, marcadas por la bondad y la novedad tautológica de los cambios, anclada en discusiones sobre acceso e infraestructura, dejando de lado un debate sobre las expresiones sociales y culturales de dichos cambios. Así nos olvidamos de un debate sobre los efectos y consecuencias concretas de estos cambios, nos alejamos de reflexiones sobre las funciones sociales que se abren y se cierran con dichos cambios, sobre su imbricación con prácticas añejas. Nos olvidamos pues de su pátina social, de su expresión localizada y contextual, de su anclaje.

Fatalismos, debates estériles y cibérboles entorpecen y distraen buena parte de las discusiones en torno al $e$ learning. Lo primero, pues, es despejar parte de estos malentendidos con preguntas que nos abran otros horizontes conceptuales. A ello nos hemos dedicado en este monográfico.

Hemos visto, por ejemplo, que los retos, los obstáculos, las definiciones, los usos y las aplicaciones varían en función de la geografía y de las condiciones socioeconómicas que rodean su desarrollo, su promoción e incluso su implantación. Es decir, que hay un primer correlato importante que debe considerarse: para comprender y desarrollar las potencialidades del $e$ learning, sobre todo desde un punto de vista social, es necesario atender a su carácter relativo, situado, contextual. Más aún si en él vemos una esperanza de transformación social.

Del e-learning hemos visto también que tiene un carácter político, si con ello entendemos que participa de manera importante en el destino de nuestras sociedades. Para bien o para mal, el suyo no es un papel neutro. Podemos decir que el e-learning no es ni bueno ni malo, pero tampoco neutro. Su desarrollo, su condición, su implantación responde a proyectos y necesidades sociales concretas, reales o deseadas, y por ello debemos aportar también esta lectura sobre aquello que le rodea y le atañe. Sólo cuando nos damos cuenta de que ejerce un papel crucial en las sociedades actuales, de que constituye una plataforma de marcada influencia y de 
extrema potencialidad, y sólo cuando vemos hasta qué punto es importante que la sociedad entera participe de sus destinos y horizontes, podemos empezar a pensar en la dirección que queremos imponerle. Es así como nos percatamos de su dimensión política; es así como empezamos a adueñarnos de las políticas implícitas o explícitas de estos operativos.

Así, cuando hablamos de e-learning no hablamos sólo de una nueva aplicación. Actualmente, conceptos como los de desarrollo, aprendizaje e incluso capital social se vinculan con exceso al e-learning mediante un discurso triunfante, instrumentalista y marcado por la mercadotecnia imperante. Esto convierte a menudo el e-learning en un producto, en una marca, en un valor más en competencia con otros, intentando venderse y hacerse un lugar del modo más atractivo en un mercado tan saturado como desalmado. Sin duda, éste no es el camino que nos permitirá salvar obstáculos, soslayar exclusiones y fracturas sociales. Cuando hablamos de $e$ learning, hablamos de las potencialidades educativas y no sólo de explotación económica y comercial de determinados medios. Hablamos de prioridades sociales, de premisas que deben responder a un interés público y colectivo por uno de los valores más preciados de las sociedades actuales: la información y el conocimiento. Más que de bienes de consumo, hablamos de deberes sociales. Es por ello que hay que situar la discusión ante estas innovaciones en un polo de responsabilidad y compromiso social, puesto que la tensión entre su comercio o uso público influye decisivamente en su uso social, en su papel integrador o en su papel a la hora de acrecentar o disminuir determinadas desigualdades.

Desde este monográfico hemos querido argumentar que en un contexto como el actual -marcado por crecientes desigualdades sociales, y por brechas que no dejan de crecer y ampliarse- es importante orientar los pasos del e-learning, lenguajearlo, de modo que pueda participar activamente en el proceso de creación de una sociedad más justa, solidaria y democrática. Más que ayudar a socavar aún más profundamente la orografía social, política y cultural de las sociedades globalizadas, el $e$ learning debe encaminarnos a retos que permitan superar los obstáculos, las fronteras, los peajes de todo tipo a los que nos enfrentamos. El suyo, sin duda, es un trabajo de ingeniería, de tendido de puentes en un momento histórico.

\section{REPENSAR LOS LÍMITES Y FINALIDADES SOCIALES DEL E-LEARNING: INCLUSIÓN Y EXCLUSIÓN}

Ante aquellos que con actitud quejumbrosa se lanzan a denunciar el poco interés social del e-learning, y su excesiva connivencia con el sistema económico vigente y sus desigualdades instituidas, se apunta a menudo la idea de que el e-learning puede ser un instrumento de transformación social importante. Se nos dice que puede, e incluso debe, ser una herramienta de inclusión social y por tanto contribuir a reducir, atajar y hasta socavar cualquier desigualdad y exclusión social vinculada a las posibilidades y condiciones para el aprendizaje y la enseñanza. Pero ¿a qué inclusión nos referimos?, ¿a qué denominamos hoy en día exclusión? Cualquier solución, por concienciada que sea, debe tener en cuenta y reflexionar profundamente sobre estas categorías cuyo sentido parece mutar con la misma celeridad que mutan nuestras estructuras y significados sociales.

En la actualidad, como afirman distintos autores, hace falta reconsiderar los mecanismos de exclusión social. Procesos sociales actuales, como el informacionalismo o la denominada globalización económica han transformado de manera importante nuestras sociedades. Dichos procesos hacen que muten rápidamente buena parte de los mimbres sociales y relacionales sobre los que edificamos nuestros colectivos, sobre los que tejemos relaciones, afectos e intercambios. $\mathrm{Al}$ variar la sustancia misma de lo social, mutan muchos de los elementos que hasta ahora nos servían para identificar sus límites, sus dinámicas y sus transformaciones. En este sentido, sin duda, el concepto de exclusión social se ha visto 
modificado. Un ejemplo lo encontramos en el trabajo de David Casacuberta: «La brecha digital es uno de los peligros más graves a la hora de consolidar un desarrollo armónico de la sociedad de la información. Se trata de una división metafórica que separa a aquellos ciudadanos que pueden usar las nuevas tecnologías en beneficio propio de aquellos que no pueden hacerlo.» ${ }^{4}$ Ello exige, de todos, un esfuerzo importante que permita ubicar las tensiones, los conflictos y las dinámicas de exclusión que son propias de las sociedades altamente informatizadas y de alcance planetario. La información —entendida en términos de acceso y circulación, pero también en términos de interpretación y significación, de codificación/descodificaciónconstituye una fuerza social motriz muy importante, y en torno a ésta se dirimen y bosquejan muchos de los nuevos conflictos y formas de exclusión social.

Del mismo modo, la polarización instituida por los flujos económicos y crecientemente deslocalizados, que caracterizan mayoritariamente las relaciones económicas actuales — del llamado «capitalismo de nuevo cuño»—, y que a menudo denominamos con el concepto de globalización, dividen buena parte del mundo entre aquellos que están globalizados y aquellos sumidos irremisiblemente a la localidad. ${ }^{5}$ Los primeros son sinónimo de movimiento y potencialidad, y exaltan la elección constante y la libertad en sus actos y expresiones, mientras que los segundos son sinónimo de exclusión, de inmovilidad y, por lo tanto, de incapacidad y sometimiento. Como vemos, pues, existen nuevas formas de conceptuar, discernir e ilustrar la exclusión social. Una exclusión muy relacionada con las formas, las premisas y las infraestructuras que les son propias y características a las sociedades actuales.

Del mismo modo que se transforma la idea de exclusión, y que debemos dirigir nuestro esfuerzo intelectual a comprender dichos cambios, debemos también considerar el cambio conceptual que recae en su palabra especular: la inclusión. Es algo que también se ha puesto de manifiesto en este workshop. Necesitamos de otros mapas para cartografiar, definir y hablar de inclusión social.

Es evidente, pues, que hay que intentar transformar también el horizonte de comprensión de la inclusión social. Y en ello hay mucho trabajo por hacer. Sin embargo, tenemos ya algunas pistas, algunas de ellas desveladas a lo largo del monográfico.

Normalmente entendemos la inclusión social como ese tendido de puentes que permite salvar el vacío o la distancia que separa puntos, condiciones sociales, beneficios y colectivos concretos. El lenguaje de la inclusión social se ha renovado durante los últimos años, pero, como han puesto de manifiesto los autores que participan en esta obra, queda mucho por hacer. Reconsiderar críticamente la inclusión social es una premisa y una labor básica que debe llevarse a cabo.

En este sentido, a lo largo del monográfico se han dado algunas claves que permiten comenzar a orientar la discusión hacia demarcaciones más fructíferas. Sin embargo, nuestro esfuerzo no ha ido encaminado a definir, delimitar o instituir una nueva definición de inclusión social. No obstante, en los textos que aquí se exponen hay ciertas apuestas, intentos, bosquejos que permiten empezar a virar el timón de nuestras concepciones sobre la inclusión social hacia otras latitudes.

La inclusión social es algo más que acceso digital o dotación de infraestructuras, incluso algo más que alfabetización tecnológica. Es cierto que hay una barrera por cuestiones meramente materiales, por cuestiones vinculadas a los recursos y a las dotaciones que se distribuyen socialmente de forma desigual y en muchos casos reflejando divisiones sociales ya existentes. De este modo, una vez más, los grupos más desfavorecidos se ven

\footnotetext{
4 CASACUBERTA, D. (2004). "E-Learning e inclusión social en el marco del sistema universitario español".

5 BAUMAN, Z. (1998). Globalització. Les conseqüències humanes. Barcelona: EDIUOC / Proa, 2001.
} 
doblemente excluidos. Sin embargo, la exclusión tiene un anclaje también cultural que no hay que soslayar. Acceder y disponer de recursos de corte intelectual, conceptual, que puedan dotar de autonomía a los sujetos es algo que sin duda se plantea poco pero que parece de trascendental importancia. «Incluir» se acerca mucho más a «dotar de autonomía»y, sobre todo, a reconstruir los lazos sociales y culturales que impiden un acceso y disfrute de dichos recursos a determinados grupos sociales.

En ese sentido las soluciones que se están aplicando hoy en día - acceso y disfrute libre, distribución libre, etc.no parecen aportar demasiado a la solución de los problemas actuales; sobre todo porque los tratan como problemas meramente técnicos, desajustes funcionales que dificultan el progreso armónico de la sociedad sin límites. No obstante, la dotación tecnológica por sí misma no solventará nada. Ninguna plataforma sirve de nada sin la legitimidad, los contenidos y el apoyo social apropiado para cada iniciativa. En eso lo que pasa en línea no difiere tanto de lo que estamos acostumbrados a experimentar fuera de línea. Seguramente, verlo así, como algunos han puesto de manifiesto, exige no sólo un cambio de horizontes sino repensar el paradigma mismo de la transformación y la inclusión social.

En este sentido hay otro corolario que se desprende del análisis efectuado por los autores: necesitamos un análisis profundo de qué tipo de distancia se intenta salvar, de qué condiciones la generan y de qué soluciones específicas requiere cada tipo de distancia para empezar a aterrizar aquello que queremos decir con inclusión (y exclusión) social y para operar en esa dirección.

En esta línea es importante apostar por la innovación, la creatividad y la calidad. Pero también es verdad que estos aspectos deben ser más una realidad que mueva el desarrollo y la implantación de plataformas de aprendizaje y educación virtuales que meras premisas integrantes de un dudoso marketing social.
Hay que ser conscientes, además, de que no es nada fácil proponer políticas de inclusión ante el crisol de condiciones distintas a las que nos enfrentamos en las sociedades actuales, y menos si descuidamos la contribución de actores sociales importantes. Instituciones, políticos, movimientos sociales y la sociedad civil en general necesitan involucrarse de algún modo para convertir la sociedad del conocimiento y de la información en una verdadera sociedad que conoce y comparte información, y que tiene una de sus prioridades en la importante tarea de aprender y enseñar. Hay que conseguir personalizar sin desconectarnos de las dinámicas globales y los condicionantes planetarios que nos embargan a todos y todas hoy en día.

Hace falta anclar la esperanza, que no sea abstracta, que no esté desprovista de la pátina social, cultural, económica que le da sentido en cada contexto, en cada situación de aprendizaje a la que pretende responder. No es suficiente con decir que el e-learning salva las distancias si desconocemos qué tipo de distancia se pretende o se está, supuestamente, salvando. ¿Hablamos de distancia social, geográfica, cultural, tecnológica? Todas ellas pueden estar relacionadas, pero todas ellas son también distintas. El polo que orienta nuestra intervención, nuestra esperanza, debería marcar las políticas de inclusión vinculadas al e-learning.

Uno de los retos al que debe hacer frente de un modo más acuciante es el de la articulación. Acercar el $e$ learning, convertirlo en un motor de transformación social y cultural, implica contar con un acerbo de actores, instituciones y recursos importante, además de conseguir que éstos trabajen en la misma dirección. Este trabajo exige consenso, esfuerzo y un esmerado compromiso de articulación que consiga reunir y orientar políticas públicas y gubernamentales con sectores privados; que consiga atraer al tercer sector; que consiga dotar de infraestructuras que resuelvan problemas de acceso; que consiga tener una relación con el imprescindible sector empresarial y competitivo, y además imprimir un marcado sentido de responsabilidad y 
justicia social a estos entramados necesarios. Todo ello, además, no tendrá sentido si no se cuenta, y mucho, con los contextos de aplicación, con los colectivos a los que se dirigen estas plataformas, con las necesidades específicas y los aprendizajes necesarios para sus usos y para explotar esas potencialidades. Es decir, de nada sirve si no buscamos apropiaciones significativas que vayan más allá de meras relaciones de beneficio y competencia.

No hay inclusión posible sin una buena detección de necesidades, sin una evaluación contextual, sin una participación de las comunidades y actores a los que se dirige, y sin una apropiación significativa por parte del contexto que condiciona las necesidades y potencialidades de estas plataformas.

\section{PERSPECTIVA SOCIAL DEL E-LEARNING Y TRANSFORMACIÓN DEL PARADIGMA EDUCATIVO}

Sin duda tenemos una oportunidad muy importante: la de hacer circular el conocimiento, la información y el saber por derroteros hasta hace poco inimaginables, haciéndolos llegar a sectores y colectivos que han quedado hasta ahora desplazados de la ruta del saber, de la información, del acceso y decisión sobre los significados y los saberes. Tenemos también que salvar un problema: que la esperanza no se convierta en condena y hundamos aún más a aquellos sobre quienes descansa el peso del privilegio de unos pocos. Y no es un riesgo baladí ni tampoco un efecto colateral: la lógica de la capitalización, de la apropiación y de los juegos de suma cero se extiende también al conocer y con ello se extiende la desigualdad y la discriminación.

Atajarlo es posible. Y el problema no es estrictamente presupuestario, como argumenta Michel Serres, ferviente defensor del potencial educativo de las tecnologías que operan en la virtualidad:

\begin{abstract}
"Una estimación presupuestaria, encargada por el Gobierno francés, para crear una universidad a distancia en un suburbio de París era tan sólo un uno por ciento de lo que costaba cualquier institución académica tradicional. 16 veces inferior a lo que costaron las cuatro paredes que albergan la biblioteca más grande de Francia. Con mucho menos, nos dice, se podría haber puesto todo el conocimiento a disposición de toda la población francesa, evitando, además, los billetes de tren que comporta todo desplazamiento."
\end{abstract}

Como nos hace ver Serres, el discurso sobre las dotaciones presupuestarias y el coste del cambio tecnológico enturbia otras discusiones más interesantes sobre los retos a los que nos dirigimos. De hecho, los costos y desigualdades que se atribuyen a estas tecnologías no son más, si acaso menos, que los que ya tenemos o hemos experimentado en otros períodos históricos.

Tampoco es sólo una cuestión de capacitación de manera asíncrona, de ofrecer información, de trabajar en red, etc., de llenarnos de estos conceptos relamidos y acicalados. Hace falta también reestructurar profundamente la enseñanza y el aprendizaje, de nutrirnos de nuevas y buenas prácticas en este sentido y de romper algunos lazos que aproximan el fenómeno educativo con soluciones y ventajas inmediatas y optimizadas más propias del reino del servicio que del bien público. Es sobre esa transformación del propio proceso de aprendizaje-enseñanza, como potencialidad social implícita en el e-learning, sobre lo que deberíamos discutir. $^{7}$

Seguramente nos encontramos en un momento histórico importante. Nunca antes fue tan fácil y económico diseminar, repartir y compartir información. Nunca antes la concentración de conocimiento tuvo menos sentido. Tenemos la posibilidad de llevar el conocimiento a todos. Democratizar uno de los aspectos más reacios a cualquier tipo de popularización: el propio

6 Fragmento extraído de una entrevista disponible en la red: http://www.nettime.org/Lists-Archives/nettime-1-9810/msg00137.html. Para más información sobre la concepción serresiana del cambio tecnológico y sus efectos educativos, consultar: http://www.eduteka.org/pdfdir/Serres.pdf.

7 Por ejemplo, sobre las repercusiones que esto tiene en la definición de roles, capacidades, recursos y procesos (actitudinales, cognitivos, institucionales) implicados de los distintos actores que participan y configuran el proceso de enseñanza-aprendizaje; sobre el rol del docente o la autonomía del estudiante; sobre la internacionalización del currículum y sus consecuencias. 
conocimiento. En esto se basa además el propio acto educativo: en tender puentes, en proporcionar conocimiento. Por lo tanto, la educación para nada deja de tener sentido en la sociedad actual, pero sí modifica buena parte de su función. Y a eso es precisamente a lo que hay que dar respuesta de una forma imaginativa, innovadora y de calidad. La sociedad entera, hoy, y no sólo los profesionales especializados, siente esa urgencia por conocer, por compartir, por educarse. Hasta el punto de que lo educativo, el propio conocer, se convierte en pilar del propio vínculo social. Y sin duda esto deberá cambiar el sistema educativo, así como su función y papel social. Es por ello que demandamos una sensibilidad política importante que promueva medidas políticas, leyes convencidas de la bondad y ayuda de tales cambios.

Estamos aún lejos de poder conocer su alcance. Seguramente serán las generaciones venideras quienes podrán ser testigos de los cambios y los derroteros emprendidos e iniciados por sus mayores. Sin embargo, sí que podemos darnos cuenta de algunos de los retos y caminos que se abren ahora ante nosotros. El de la inclusión social es sin duda uno de ellos, de los más acuciantes. Es importante no crear ni acentuar desigualdades, así como revertir las que podamos.

En una sociedad en la que se dan la mano conceptos como los de integración, escolarización profesional y educación, las plataformas de educación virtual a buen seguro tienen mucho que decir y mucho por hacer. Incluir socialmente pasa, y pasará cada vez más, por hacer un uso extensivo de la educación, de calidad y ajustado a las necesidades particulares de cada grupo o condición. Compartir conocimiento y dejar de capitalizarlo es una de las primeras medidas encaminadas a reintegrar colectivos y deshacer algunas de las desigualdades, heredadas o no.

\section{LA UNIVERSIDAD: UN ACTOR IMPRESCINDIBLE}

Siempre se dice que la universidad refleja las tensiones y problemáticas propias de la sociedad en la que se ubica. Sin embargo, también trasciende a menudo su función de espejo. En muchos casos, y en casi todos los períodos de la historia, la universidad ha sido un motor — si no el motor- al que la sociedad ha acudido para buscar formas y modelos de convivencia, fórmulas para atajar y combatir nuevos retos y soluciones ante determinados problemas sociales. En ella ha creído en tanto que acerbo de conocimientos, pero también en tanto que centro ejemplar, modélico o piloto. En muchos períodos de la historia, la universidad ha conjugado ambas demandas y se ha convertido en una institución reputada y privilegiada en la historia de las sociedades que la cobijan. Una vez más la universidad puede jugar ese papel ejemplar. La universidad tiene la oportunidad, aliada con el reino de lo virtual y de las lanzaderas tecnológicas que nos conectan y con las que podemos comunicarnos en formatos y límites nuevos, de pilotar de nuevo las sociedades y de aportar soluciones imaginativas a los retos y problemas que afectan a estas sociedades actuales.

Este monográfico ha pretendido destacar este papel de la universidad en la constitución de una sociedad de la información y el conocimiento justa, democrática y socialmente responsable.

Del mismo modo que debemos deshacernos de ciertos debates que se muestran estériles (apocalípticos o integrados), que sumen el pensamiento en dicotomías falsamente excluyentes y en antinomias vacías, debemos llenar nuestras reflexiones de formas de mirar y lenguajear el e-learning más fértiles, arriesgadas y creativas. En este sentido hemos intentado pensar sobre el papel de la pedagogía, y sus medios y recursos, en la superación de las barreras que obstaculizan un desarrollo armónico de la sociedad de la información y el conocimiento. En concreto, el papel del e-learning y de la educación superior.

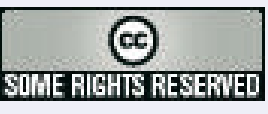

os textos publicados en esta revista están sujetos -si no se indica lo contrario- a una licencia de Reconocimiento 3.0 España de Creative Commons. Puede copiarlos, distribuirlos, comunicarlos públicamente y hacer obras derivadas siempre que reconozca los créditos de las obras (autoría, nombre de la revista, institución editora) de la manera especificada por los autores o por la revista. La licencia completa se puede consultar en http://creativecommons.org/licenses/by/3.0/es/deed.es. 